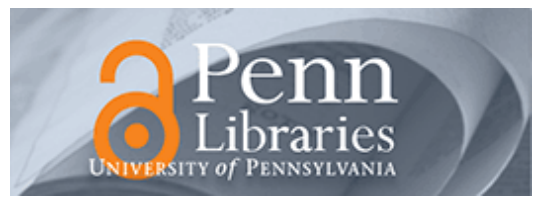

University of Pennsylvania

ScholarlyCommons

Health Care Management Papers

Wharton Faculty Research

2013

\title{
The Impact of Health Information Technology on Hospital Productivity
}

Jinhyung Lee

Jeffrey S. McCullough

Robert J Town

University of Pennsylvania

Follow this and additional works at: https://repository.upenn.edu/hcmg_papers

Part of the Health Information Technology Commons, Health Services Research Commons, and the Labor Economics Commons

\section{Recommended Citation}

Lee, J., McCullough, J. S., \& Town, R. (2013). The Impact of Health Information Technology on Hospital Productivity. The RAND Journal of Economics, 44 (3), 545-568. http://dx.doi.org/10.1111/

1756-2171.12030

This paper is posted at ScholarlyCommons. https://repository.upenn.edu/hcmg_papers/87

For more information, please contact repository@pobox.upenn.edu. 


\title{
The Impact of Health Information Technology on Hospital Productivity
}

\author{
Abstract \\ Health information technology (IT) has been championed as a tool that can transform health care \\ delivery. We estimate the parameters of a value-added hospital production function correcting for \\ endogenous input choices to assess the private returns hospitals earn from health IT. Despite high \\ marginal products, the total benefits from expanded IT adoption are modest. Over the span of our data, \\ health IT inputs increased by more than $210 \%$ and contributed about $6 \%$ to the increase in value-added. \\ Not-for-profits invested more heavily and differently in IT. Finally, we find no compelling evidence of labor \\ complementarities or network externalities from competitors' IT investment. \\ Disciplines \\ Health Information Technology | Health Services Research | Labor Economics
}


NBER WORKING PAPER SERIES

THE IMPACT OF HEALTH INFORMATION TECHNOLOGY ON HOSPITAL PRODUCTIVITY

\author{
Jinhyung Lee \\ Jeffery S. McCullough \\ Robert J. Town \\ Working Paper 18025 \\ http://www.nber.org/papers/w18025
NATIONAL BUREAU OF ECONOMIC RESEARCH
1050 Massachusetts Avenue
Cambridge, MA 02138 \\ April 2012
}

Support was provided by a grant from Robert Wood Johnson Foundation through the Changes in Health Care Financing and Organization initiative (Grant no. 64845).We thank Amil Petrin and Bryan Dowd for their helpful comments. The views expressed herein are those of the authors and do not necessarily reflect the views of the National Bureau of Economic Research.

NBER working papers are circulated for discussion and comment purposes. They have not been peerreviewed or been subject to the review by the NBER Board of Directors that accompanies official NBER publications.

(C) 2012 by Jinhyung Lee, Jeffery S. McCullough, and Robert J. Town. All rights reserved. Short sections of text, not to exceed two paragraphs, may be quoted without explicit permission provided that full credit, including $\odot$ notice, is given to the source. 
The Impact of Health Information Technology on Hospital Productivity

Jinhyung Lee, Jeffery S. McCullough, and Robert J. Town

NBER Working Paper No. 18025

April 2012

JEL No. D24,L31

\begin{abstract}
$\underline{\text { ABSTRACT }}$
The US health care sector is, by most accounts, extraordinarily inefficient. Health information technology (IT) has been championed as a tool that can transform health care delivery. Recently, the federal government has taken an active role in promoting health IT diffusion. There is little systematic analysis of the causal impact of health IT on productivity or whether private and public returns to health IT diverge thereby justifying government intervention. We estimate the parameters of a value-added hospital production function correcting for endogenous input choices in order to assess the private returns hospitals earn from health IT. Despite high marginal products, the potential benefits from expanded IT adoption are modest. Over the span of our data, health IT inputs increased by more than $210 \%$ and contributed about $6 \%$ to the increase in value-added. Virtually all the increase in value-added is attributable to the increased use of inputs \{ there was little change in hospital multi-factor productivity. Not-for-profits invested more heavily and differently in IT than for-profit hospitals. Finally, we find no evidence of labor complementarities or network externalities from health IT.
\end{abstract}

Jinhyung Lee

University of Texas - Galveston

301 University Boulevard

Galveston, Texas 77555-0133

jinlee@utmb.edu

Jeffery S. McCullough

University of Minnesota

MMC 729

420 Delaware St., SE

Minneapolis, MN 55455

mccu0056@umn.edu
Robert J. Town

Health Care Management Department

The Wharton School

University of Pennsylvania

3641 Locust Walk

Philadelphia, PA 19104

and NBER

rtown@wharton.upenn.edu 


\section{Introduction}

By most accounts, the US health care sector is inefficient. Health policy commentators have long advocated increased health information technology (IT) adoption as a means of increasing health care quality while constraining costs. The Institute of Medicine for example, has advocated increased health IT investments (Institute of Medicine, 1999, 2001, 2003; Hillestad et al., 2005). Similarly, health policy analysts have noted that other OCED countries utilize more health IT than the US and this is an important reason that health care costs are lower in the OCED. The implication is that if the US deepened their use of health IT, it will move the US towards the productive frontier for health care delivery.

In response to this call, the federal government has made increasing IT investments by private health care providers a priority. In 2004, President Bush established the National Coordinator (ONC) for Health Information Technology which is tasked with the development and implementation of a strategic plan to guide the nationwide implementation of health IT. In 2009, as part of the American Recovery and Reinvestment Act, President Obama signed the Health Information Technology for Economic and Clinical Health (HITECH) act which allocates an estimated $\$ 27$ billion in incentive payments for hospitals and health professionals to adopt and effectively use certified electronic health records (ARRA, 2009). ${ }^{1}$ Furthermore, hospitals that fail to achieve the "meaningful use" of health IT by 2015 will face reductions in Medicare payments.

The significant role the federal government plays in promoting the adoption and diffusion of health IT suggests a divergence between the private incentives and social benefits to adopting these technologies. Despite the widespread belief that health IT can address many of the health care system ailments and innumerable studies in the medical and health services research literature (virtually all with questionable identification strategies or generalizability), there is little consensus regarding the impact of health IT on provider costs and

\footnotetext{
${ }^{1}$ The cause of increasing health IT spending has been advocated at the highest levels of the federal government. On January 3, 2009 radio address, President Obama stated, "We will update and computerize our health care system to cut red tape, prevent medical mistakes, and help reduce health care costs by billions of dollars each year."
} 
revenues or the quality of care patients receive. ${ }^{2}$ This literature also points to the difficult IT investment decisions hospitals face because of the significant costs associated with large-scale health IT implementation and a priori uncertainty over the returns hospitals can expect from implementing health IT. We provide evidence on the impact of IT investments on hospital productivity to assess the private benefits from hospitals' adoption of health IT.

More recent econometric studies have found that hospital IT investments have either modest or no impact on clinical outcomes. Tucker and Miller (2011) and McCullough et al. (2010) find that the adoption of electronic medical records (EMRs) and complementary technological inputs provide positive but limited clinical benefit. McCullough et al. (2010) find a heterogeneous and modest impact of health IT where only the most severely ill benefit from health IT. However, Agha (2011) finds that hospital IT adoption does not improve mortality. In other contexts, however, IT adoption has been shown to improve health outcomes (Athey and Stern, 2002). Even if we assume that hospital IT does increase the quality of care, unless hospitals can translate these quality gains into higher profits either through higher prices or creating higher patient volumes, they will not capture these social gains. Hospitals face several challenges in transforming these quality of care improvements into profits. Evidence from the introduction of hospital report cards suggest that patient preferences are weakly related to measurable quality and therefore hospital volumes are not likely to be affected by health IT utilization (Culter et al., 2004). Typically, 50\% of hospital revenues are from publicly insured patients where hospitals are reimbursed according to a fee schedule. These fee schedules limit hospitals' ability to charge higher prices for improved quality care; although, quality improvements may reduce length of stay which, in turn, could reduce costs. Hospitals' inability to profit from IT-driven quality improvements may lead to inefficiently low IT investments. ${ }^{3}$

\footnotetext{
${ }^{2}$ Recent surveys of the literature (Buntin et al., 2011; Lapointe et al., 2011; Black et al., 2011) provide mixed evidence regarding the effect of health IT on quality and limited evidence regarding the effect of health IT on productivity. The typical paper in this literature focuses on single-site studies of IT adoption by academic medical centers.

${ }^{3}$ Prior to 2002, Medicare reimbursements partially covered hospital capital (but not labor) expenditures (Acemoglu and Finkelstein, 2008). The presence of this subsidy could spur hospitals to make significant investments in health IT, however, this capital investment subsidy ended prior to the period when sophisticated EMR and CPOE systems began diffusing widely.
} 
Hospitals' IT investments may affect productivity through a variety of mechanisms. Hospitals may benefit from the same information systems employed in other service industries. Applications such as supply chain management, accounting, and billing would, for example, lead to reduced transaction costs and more efficient resources allocation. Most, if not all, of the returns from these applications should be internalized by hospitals. ${ }^{4}$ The consequences of clinical systems, such as EMRs, are more complicated. While these systems may improve resource allocation and revenue management, they are also designed to increase clinical quality. Although quality improvement may lead to increased revenues, regulated prices and imperfect quality information may cause the social returns to exceed the private returns from health IT investments. This divergence between social and private benefits may lead to an underinvestment in quality.

In order to understand the impact of health IT on hospital productivity, we estimate the parameters of a value-added hospital production function where we decompose the key hospital productive inputs into conventional and IT categories. In our analysis, the productive inputs are labor, capital, health IT labor, and health IT capital. A well-known challenge to estimating production function parameters is that inputs are endogenous to unobserved (by the econometrician) productivity shocks (Marschak and Andrews, 1944; Ackerberg et al., 2006a,b). Over the last decade and a half, several different approaches have been proposed to correct for the endogeneity of input choice including Olley and Pakes (1996), Blundell and Bond (1998), Levinsohn and Petrin (2003) and Ackerberg et al. (2006b). These approaches are differentiated regarding assumptions on the evolution of multi-factor productivity (MFP) and in the timing of input choices. We employ each of these strategies but emphasize parameter estimates generated using the dynamic panel data (DPD) approach (Arellano and Bond, 1991; Arellano and Bover, 1995; Blundell and Bond, 1998, 2000) for ease of exposition. By using a variety of approaches we assess the robustness of our estimates. Ultimately, our primary conclusions are not sensitive to our focus on the DPD approach.

\footnotetext{
${ }^{4}$ Motivated by the approach of Brynjolfsson and Hitt (1996), recent work estimates the productivity impact of health IT using discrete measures of health IT component adoption (e.g. EMR). Parente and Horn (2007), Borzekowski (2009) and Hitt (2010) estimate production and cost functions in a simple, fixed effect framework. In each paper, IT was found to create modest efficiency gains.
} 
We employ data from California's Office of Statewide Health and Policy and Development (OSHPD) for the 11-year period from 1997-2007. The OSHPD data are well-suited (perhaps uniquely so) to examine the productivity impact of health IT as it includes detailed, hospitalspecific, information on health IT expenditures and depreciation which we use to construct measures of the dollar value of health IT capital. We know of no other data set that has this detailed financial and health IT expenditure information. This period saw a rapid diffusion of health IT, and, over the span of our data, hospitals dramatically increased their IT investments. The average hospital expanded their IT capital stock by approximately $220 \%$ over the 11-year span of our data. We supplement these data with information on the specific health IT components adopted by the hospitals from the Health Information Management Systems Society (HIMSS).

In addition to its health policy relevance, hospitals are an attractive setting to study the impact of IT investments on organizational productivity. Hospitals are the one of the largest industry in the US economy accounting for $5.3 \%$ of GDP and hospitals services are an industry in which technological change has a large impact on costs and consumer welfare (Cutler, 2004). Hospitals are extremely complex, hierarchical, compartmentalized, and labor-intensive organizations where information creation and dissemination is central to its operation. Inpatient care requires the coordination of activities across many workers with diverse skill levels in which errors are potentially costly to both the hospital and the patient. Hospitals have well-documented challenges managing their information. ${ }^{5}$ Because of this complexity, hospitals are an environment in which IT has the potential to significantly improve work flow, communication and coordination.

The large literature studying the productivity impact of IT adoption principally analyzes data generated prior to 2000 - a period when the PC revolution was of central interest to this literature (Tambe and Hitt, 2010). ${ }^{6}$ Our analysis focuses on a recent period of time when new information technologies were rapidly and broadly diffusing providing an excellent environment to study the impact of recently developed IT. ${ }^{7}$ Furthermore, most of the previous

\footnotetext{
${ }^{5}$ Institute of Medicine (1999).

${ }^{6}$ A classic paper in this literature is Brynjolfsson and Hitt (1996).

${ }^{7}$ Tambe and Hitt (2010), Bloom et al. (2012) and Bartel et al. (2007) are three notable exceptions to the
} 
work on IT productivity uses data from spanning broad classes of industries and types of organizations with a focus on very large firms. Because we study a single type of organization, acute-care hospitals, we eliminate an important source of unobserved heterogeneity that might affect cross-industry studies. While hospitals are broadly homogeneous over the types of services they provide, they are heterogeneous with respect to size and ownership structure so we can examine how these organizational differences affect the impact of health IT.

We find that both health IT capital and labor have a high, private marginal product increases in health IT significantly increase hospital value-added. At the median, the net marginal product of IT capital is approximately $\$ 1.04$ and the net marginal product of IT labor is about $\$ 0.73$. These estimates imply that marginal increases in health IT can generate substantial increases in output. However, the absolute contribution of IT investments are small and diminishing. From 1997 to 2007, the average hospital value-added increased 156\%, about $6 \%$ is attributable to investments in health IT capital and labor. Unless there is a dramatic change in the state of health IT technology (which is certainly possible), our estimates imply that the large expected increase in hospitals' IT capital stock will have a modest impact on value-added output.

A classic reason for the divergence between public and private benefits from technology adoption the presence of network externalities (Katz and Shapiro, 1986). Network externalities have been found to affect technology adoption directly, through interoperable technologies, and indirectly through learning spillovers. We directly test for the presence of network externalities in productivity using a similar identification strategy to Gowrisankaran and Stavins (2004). We find no evidence of meaningful network externalities in health IT. ${ }^{8}$

Our data also allow us to examine three important ancillary questions: 1) Is there differential behavior between for-profit (FP) and not-for-profit (NFP) hospitals in their IT investments? 2) Are vintage or learning effects in health IT important? 3) What is the role of the change in multi-factor productivity in the increase in hospital value-added?

We also find that FP hospitals invest less in overall health IT and are less likely to literature's focus on firm-level data prior to 2000.

${ }^{8} \mathrm{~A}$ recent survey of hospital health IT adoption asked about the factor inhibiting adoption and the responses did not point to network externalities (Jha et al., 2008). 
adopt CPOE technologies. However, production function estimates indicate little difference between FP and NFP hospitals' abilities to translate health IT investments into productive output. As for our second, ancillary question, the parameter estimates hint that later health IT investments are more productive than investments made at the beginning of our sample while the employment of health IT labor is significantly more productive in the last half of our time frame than in the first half. Finally, we find that increased hospital productivity from 1997-2007 is entirely driven by increased inputs.

Our results have important policy implications. Health IT appears to be very productive at the margin. Hospitals appear to under-invest in health IT despite relatively high private returns. Nevertheless, given the current state of the technology and our estimates of diminishing returns, broad expansions in health IT would have a small impact on hospital productivity. This implies that while government funding for increased EMR adoption may be welfare enhancing, they will not transform health care delivery. This result is also consistent with the findings that a broad increase in EMR adoption will only have a modest impact on mortality (Agha, 2011; McCullough et al., 2011; Tucker and Miller, 2011). The gains from implementing these technologies appear to be well captured by hospitals and our findings do not suggest the presence of network externalities. Finally, NFP and FP hospitals' differ in their health IT utilization.

The rest of the paper has the following structure. The next section provides some institutional background on hospital IT. Section 3 describes our empirical model and describes our empirical model and Section 4 discusses our data sources. Section 5 discusses the basic patterns in the data and trends in health IT adoption. Section 6 presents and discusses the production function estimates. Section 7 concludes.

\section{Background - Hospital Information Technology}

Hospitals began investing in health IT during the 1960s. Information technology was first used to support billing and financial services. Subsequently, the role of IT grew to manage pharmacy, laboratory, and radiology service lines (Collen, 1995). Although their primary 
purpose was to support billing and capture revenues (commonly referred to as charge capture) these applications began to monitor and support basic clinical activities. These systems frequently provided services such as drug interaction controls, laboratory quality controls, and documentation of patient's radiology histories. These systems were nearly ubiquitous by 2000 (McCullough, 2008).

The development of electronic medical record (EMR) systems has greatly expanded the automation of clinical services. These systems replace a hospital's medical record and integrate clinical information from ancillary services such as pharmacy, radiology, and laboratory. More sophisticated systems allow physicians to directly access the electronic medical record and enter orders electronically. Computerized providers order entry (CPOE) is intended to reduce communication errors and serve as a platform for treatment guideline automation. While leading academic medical centers have been developing these technologies for many years, it is only during the past decade that this technology has begun to diffuse widely.

Information technology can affect hospital productivity through a variety of mechanisms. While hospitals may gain the same benefits from IT as any other service firm (e.g., improved supply chain management or enhanced labor productivity), three mechanisms are particularly important for hospitals: billing management, provider monitoring, and clinical decision support.

Improved billing may be the most widespread effect of hospital IT investments. Hospitals provide a wide range of services and the prices of these services depend upon patients' clinical characteristics as well as contracts negotiated between payers and providers. For example, the reimbursement rate for cardiac surgery often depends upon whether a patient is a diabetic or has hypertension as these comorbidities affect hospital costs. Price schedules and clinical documentation requirements depend on contracts with private insurers as well as government regulations. While hospitals have long used conventional IT for billing support, EMRs are increasingly used to document care and facilitate charge capture.

Clinical complexity also creates a difficult monitoring problem. Although physicians control most hospital resources their actions are difficult to document and evaluate. Furthermore, most physicians are employed by physician-owned practices rather than hospitals. Hospitals 
use IT to monitor physician behavior. Relatively simple clinical information systems may be used to generate periodic reports on physician behavior and resource utilization. These reports may be used to support quality improvement initiatives or to identify the overuse of laboratory and radiology resources. Comprehensive EMR systems allow for much more sophisticated provider monitoring and may lead to improved resource allocation within hospitals.

Clinical decision support is the most ambitious objective of hospital IT. Sophisticated EMR systems with CPOE may be used as a platform to implement treatment guidelines, identify dangerous drug interactions, or coordinate care across provider team members. These real-time decision support functions should standardize care and reduce errors, thus enhancing both clinical quality and productivity.

Decision support systems are more effective when they possess detailed information regarding patients' clinical characteristics and treatment histories. Thus, EMRs may exhibit network externalities as their value could increase if neighboring providers adopted interoperable EMRs. Although EMRs with real-time clinical decision support among the mostdiscussed forms health IT, Jha et al. (2009) find that information sharing across providers is quite rare.

Most of these productivity-enhancing mechanisms should be captured by conventional measures of value added. Quality changes may, however, be omitted from value added if they do not lead to increases in prices or quantities. This may be important for hospitals as quality is difficult to measure and the prices for many patients (i.e., Medicare beneficiaries) are fixed by law. A number of recent economic studies provide evidence that although EMRs may improve quality, the average effect is quite small (McCullough et al., 2010; Agha, 2011; McCullough et al., 2011; Tucker and Miller, 2011).

\section{Empirical Strategy}

We model value-added output for hospital $i$ in period $t\left(Y_{i t}\right)$ as determined by a Cobb-Douglas production function whose inputs are conventional labor $\left(L_{i t}\right)$, conventional capital $\left(K_{i t}\right)$, IT 
labor $\left(L_{i t}^{c}\right)$, IT capital $\left(K_{i t}^{c}\right)$, and an unobserved (to the econometrician) input $\epsilon_{i t} \cdot{ }^{9,10}$ We use lower-case variables to denote logarithms and denote the logarithm of the entire set of inputs used by the hospital by the vector $x_{i t}$. The starting point for our analysis is the following value-added production function, ${ }^{11}$

$$
y_{i t}=\beta_{l} l_{i t}+\beta_{k} k_{i t}+\delta_{l} l_{i t}^{c}+\delta_{k} k_{i t}^{c}+\epsilon_{i t} .
$$

Where $\beta_{l}, \beta_{k} \delta_{l}$, and $\delta_{k}$ are output elasticities of their respective inputs. We are primarily interested in the $\delta$ 's which measure health IT's contribution to output. The multi-factor productivity term, $\epsilon_{i t}$, is unobserved to us, but may be observables to hospitals when selecting inputs. We decompose this unobserved term into four components:

$$
\epsilon_{i t}=\alpha_{i}+\gamma_{t}+\omega_{i t}+\eta_{i t}
$$

The first term, $\alpha_{i}$, is a time-invariant hospital fixed effect while $\gamma_{t}$ is a common, time varying productivity shock. Both $\alpha_{i}$ and $\gamma_{t}$ may be correlated with the inputs. The evolving, unobserved (to us) productivity term, $\omega_{i t}$, may also be correlated with the inputs. Finally, $\eta_{i t}$ is a productivity shock that may be correlated with inputs choices and may evolve according to a moving average process.

Correlation between the inputs and $\epsilon_{i t}$ implies that standard approaches to parameter estimation will be biased. The appropriate econometric approach to remove the bias depends upon assumptions regarding the variation in $\alpha_{i}$, the evolution of $\omega_{i t}$, and the timing of input

\footnotetext{
${ }^{9}$ This section draws heavily upon the work of Ackerberg et al. (2006b).

${ }^{10}$ We measure output using value-added, a common measure of output in productivity studies (e.g. Levinsohn and Petrin (2003)). That is, $y_{i t}$ is operating revenues net of all intermediate inputs. We use this output measure for two reasons. First, hospitals produce multiple products and these must be aggregated into a single output measure. In effect, value-added aggregates across many different services weighted by the revenue associated with that service. Second, production is heterogeneous across hospitals. The value-added production function accounts for aspects of quality reflected in market prices and quantities.

${ }^{11}$ The IT productivity literature primarily employs the Cobb-Douglas production function in their analyses (Brynjolfsson and Hitt, 1996, 2003; Stiroh, 2002) and it is the specification of choice in dynamic panel environments (Arellano and Bond, 1991; Arellano and Bover, 1995; Blundell and Bond, 1998, 2000). We follow this literature and assume Cobb-Douglas production relationship. However, it is well known that the Cobb-Douglas function imposes strong parametric relationships on marginal products, a relationship that we are particularly interested in quantifying in this paper. We have explored using a less restrictive trans-log production function and the estimates did not reject the Cobb-Douglas specification.
} 
selection (Ackerberg et al., 2006b). Consequently, we estimate the parameters of (1) under several different assumptions over $\alpha_{i}$ and $\omega_{i t}$ and compare these estimates to assess the robustness of our conclusions to different functional form and identification assumptions.

Our baseline empirical strategy is the dynamic panel data (DPD) approach of Arellano and Bond (1991), Arellano and Bover (1995), and Blundell and Bond (1998, 2000). Returning to equations (1) and (2), we assume that $\omega_{i t}$ evolves according to an autoregressive process. Let $\xi_{i t}$ be an iid random shock, then $\omega_{i t}$ follows the first-order autoregressive process, $\omega_{i t}=$ $\rho \omega_{i t-1}+\xi_{i t}$. The key assumption is that the innovation in unobserved productivity, $\xi_{i t}$, is uncorrelated with $x_{i s} \forall s \leq t$ while $\epsilon_{i t}$, which contains a hospital fixed-effect as well as an evolving productivity component, but may be correlated with $x_{i t}$. This dynamic panel data model is attractive in our setting as it allows a time-invariant fixed-effect in the evolution of unobserved productivity. Many hospital characteristics such as its location and religious affiliation are time-invariant, while other aspects of hospital productivity (e.g. physician affiliation and reputation) evolve over time. The DPD framework allows for these institutional features. Solving for $\omega_{t-1}$ and substituting into (1) yields the dynamic factor (common factor) representation:

$$
\begin{array}{r}
y_{i t}=\rho y_{i t-1}+\beta_{l} l_{i t}-\rho \beta_{l} l_{i t-1}+\beta_{k} k_{i t}-\rho \beta_{k} k_{i t-1}+\delta_{l} l_{i t}^{c}-\rho \delta_{l} l_{i t}^{c}+\delta_{k} k_{i t}^{c}-\rho \delta_{k} k_{i t-1}^{c} \\
+\gamma_{t}-\rho \gamma_{t-1}+\alpha_{i}-\alpha_{i} \rho+\xi_{i t}+\eta_{i t} .
\end{array}
$$

or

$$
\begin{aligned}
y_{i t}=\pi_{1} y_{i t-1}+\pi_{2} l_{i t}+\pi_{3} l_{i t-1}+\pi_{4} k_{i t}+\pi_{5} k_{i t-1}+\pi_{6} l_{i t}^{c}+\pi_{7} l_{i t}^{c}+\pi_{8} k_{i t}^{c}-\pi_{9} k_{i t-1}^{c} & \\
& +\gamma_{t}^{*}+\alpha_{i}^{*}+\xi_{i t}+\eta_{i t} .
\end{aligned}
$$

Where $\pi_{3}=-\pi_{1} \pi_{2}, \pi_{5}=-\pi_{1} \pi_{4}$, and $\pi_{7}=-\pi_{1} \pi_{6}$. Furthermore, $\alpha_{i}^{*}=\alpha_{i}(1-\rho)$ and $\xi_{i t}^{*}=\xi_{i t}+\eta_{i t}$

We start by estimating the parameters using equation (4) via OLS and fixed-effects imposing (and testing) the common factor restrictions. OLS will, of course, only be consistent under the restrictive assumption that $E\left(\alpha_{i}^{*} x_{i t}\right)=0, E\left(\xi_{i t} x_{i t}\right)=0$ and $E\left(\eta_{i t} x_{i t}\right)=0$ while the 
fixed effects estimator will generate consistent estimates if $E\left(\xi_{i t} x_{i t}\right)=0$ and $E\left(\eta_{i t} x_{i t}\right)=0$.

For the base specification, we employ a system GMM estimator. This approach simultaneously estimates the equation of interest using both levels and differences specifications. Appropriate lags of the levels and differenced variables can be used as instruments. Lagged levels are used as instruments for the differences equation while lagged differences are used as instruments for the differences equation. This simultaneous estimation strategy results in lower finite sample bias and increased precision. Specifically, this approach uses the following moment conditions:

$$
\begin{gathered}
E\left[\Delta x_{i t-s}\left(\alpha_{i}^{*}+\xi_{i t}^{*}\right)\right]=0 \quad \text { and } E\left[\Delta y_{i t-s}\left(\alpha_{i}^{*}+\xi_{i t}^{*}\right)\right]=0, \quad \text { for } \quad s \geq 1 \text { and } t \geq 3, \\
E\left[x_{i t-s} \Delta \xi_{i t}^{*}\right]=0 \text { and } E\left[y_{i t-s} \Delta \xi_{i t}^{*}\right]=0, \quad \text { for } \quad s \geq 2 \text { and } t \geq 3,
\end{gathered}
$$

More generally, the values of $t$ and $s$ are determined by the assumption on the autocorrelation structure in $\eta_{i t}$. This assumption can be validated by testing whether the first differenced residuals' exhibit second-order serial correlation. The specification tests indicated that $s=3$ removes the serial correlation and is used in the estimation. Since the model is over-identified we employ the Hansen test for instrument validity.

We also estimate the parameters in (1) using the econometric strategies of OP, LP and ACF. At one level, these three models are similar as they all employ two-step estimators that use proxy variables to control for the productivity shocks thereby removing the bias. At another level, these three models make different assumptions on both the proxy variable and the timing of input decisions which may have large implications for identification (Ackerberg et al., 2006b). Specifically, OP uses investment as the proxy variable while LP uses material inputs and $\mathrm{ACF}$ considers both investments and material inputs. We first focus on the ACF approach and then discuss both LP and OP.

Returning to equation (2), ACF assume that $\epsilon_{i t}=\omega_{i t}+\eta_{i t}$ - the hospital fixed effect is dropped from this specifications. A first-order Markov process governs the transitions of $\omega_{i t}$ between periods $t$ and $b$. That is, $p\left(\omega_{i t+1} \mid I_{i t}\right)=p\left(\omega_{i t+1} \mid \omega_{i t}\right)$ where $p(\cdot \mid \cdot)$ denotes the density function and $I_{i t}$ is the information set. Under ACF, labor and capital (both conventional 
and IT) are assumed to be chosen prior to period $t$. Given these assumptions, the hospital's materials input demand, $m_{i t}$, is given as: $m_{i t}=f\left(\omega_{i t}, l_{i t}, k_{i t}, l_{i t}^{c}, k_{i t}^{c}\right)$. Inverting this equation and substituting back into (1) and (2) yields:

$$
y_{i t}=\beta_{l} l_{i t}+\beta_{k} k_{i t}+\delta_{l} l_{i t}^{c}+\delta_{k} k_{i t}^{c}+f^{-1}\left(m_{i t}, l_{i t}, k_{i t}, l_{i t}^{c}, k_{i t}^{c}\right)+\eta_{i t} .
$$

The $\beta$ 's and $\delta$ 's are not separately identified in equation (7). ACF's strategy is to estimate $y_{i t}=\Phi\left(m_{i t}, l_{i t}, k_{i t}, l_{i t}^{c}, k_{i t}^{c}\right)$ nonparametrically in a first stage. We estimate $\Phi$ using a second order polynomial. In the second stage, estimates of $\omega_{i t}\left(\beta_{l}, \beta_{k}, \delta_{l}, \delta_{k}\right)=\hat{\Phi}-\beta_{l} l_{i t}-\beta_{k} k_{i t}-\delta_{l} l_{i t}^{c}-$ $\delta_{k} k_{i t}^{c}$ are constructed. $\omega_{i t}$ is then nonparametrically regressed on $\omega_{i t-1}$ and $\eta_{i t}$ is calculated. Production function parameters are then identified from the following moment condition:

$$
E\left(\eta_{i t} \cdot z_{i t}\right)=0
$$

where $z_{i t}=\left(l_{i t-1}, k_{i t}, l_{i t-1}^{c}, k_{i t}^{c}\right)$.

We also estimate the parameters using the LP and OP approaches. Both LP and OP assume that $l_{i t}$ is chosen knowing $\omega_{i t}$. This implies a different moment condition in which contemporaneous labor replaces lagged labor in (8). LP use materials as the proxy variable while OP uses investment and those differences may or may not be important depending on the distribution of investment and the underlying reasons for the lag in the timing of input choices. ${ }^{12}$ Both approaches identify the labor coefficients in the first stage. The LP moment condition used to identify the capital coefficient replaces $m_{i t-1}$ for $l_{i t-1}$ while the OP moment condition is simply $E\left(\eta_{i t} k_{i t}\right)=0$. Although the LP and OP approaches have been widely used, ACF notes that they face potential identification problems due to the collinearity in input choices. ACF further argue that this concern does not apply to their approach.

There are distinct advantages and disadvantages of the DPD and the ACF/LP/OP approaches. As discussed above, an advantage of the DPD approach in our setting is that it allows for a time-invariant hospital fixed effect. The DPD approach is also consistent

\footnotetext{
${ }^{12} \mathrm{LP}$ point out that if there is a mass point in investment at zero (which is common for smaller firms), the necessary inversion of the $f$ function does not exist. In our case this is not important as hospitals always make positive investments in our data.
} 
with more complex models of input demand frictions (e.g. adjustment costs or labor shortages) and can accommodate multivariate productivity shocks while ACF/LP/OP place more restrictions on the underlying input demand model. ACF/LP/OP require a univariate unobservable productivity shock and input demand must be monotonic in $\omega_{i t}$ for at least one input. For example, in an adjustment cost framework input demand is a function of lagged values of the productivity shock and this is not consistent with the ACF framework (Bond and Soderbom, 2005). Conversely, the DPD approach imposes a linear autoregressive structure on the evolution of $\omega_{i t}$, while $\mathrm{ACF} / \mathrm{LP} / \mathrm{OP}$ allow $\omega_{i t}$ to follow an arbitrary first-order Markov process. $\mathrm{ACF} / \mathrm{LP} / \mathrm{OP}$ estimate $\Phi$ nonparametrically. Finally, DPD is likely asymptotically less efficient than $\mathrm{ACF} / \mathrm{LP} / \mathrm{OP}$.

Each of the above approaches has clear advantages and disadvantages; furthermore, there are no obvious specification tests for determining which model is most appropriate. ACF recommends examining the robustness of parameter estimates using several different approaches. While we emphasize the DPD model for ease of exposition, all four estimation strategies are employed in our analysis and each provides insight into the hospital production process.

\subsection{Ownership differences, network externalities and vintage ef- fects}

In addition to estimating the impact of IT inputs on productivity we explore other dimensions of the data to better understand the underlying relationship between IT and value-added. There are four areas of interest: the impact of for-profit status, network effects, vintage effects, and the impact of hospital size.

Not-for-profit and for-profit hospitals may have differing organizational objectives which lead them to use IT differently. There is a long literature examining the differential behavior of for-profit and not-for-profit hospitals. ${ }^{13}$ This body of work typically finds little difference in behavior across these organizational forms. However, more recent research points to forprofit hospitals investing in more profitable services and avoiding the least profitable services

\footnotetext{
${ }^{13}$ See Sloan (2000) for an excellent review of the literature on the role of ownership status and provider behavior.
} 
relative to their not-for-profit counterparts (Horowitz and Nichols, 2009; David et al., 2011). If hospitals cannot appropriate a significant portion of the returns to IT investments and if NFPs have different long-run objectives than FPs, then IT investment strategies should differ across ownership forms. Differential investment behavior across ownership forms may have meaningful policy implications. Differential investment strategies may partially justify the tax-exempt status of not-for-profit hospitals and may suggest the need to target health IT subsidies (or penalties) based on ownership. To explore whether the productivity of IT investments differs across ownership form, we split the sample and estimate production function parameters separately for each hospital type.

A classic explanation for the divergence between public and private benefit of IT is network externalities (Katz and Shapiro, 1986). Network externalities have been found to affect technology adoption directly, through interoperable technologies, and indirectly through learning spillovers. There is, however, little empirical evidence regarding network effects in the productive value of health IT. As discussed in Section 2, cross-provider information sharing is argued to be an important driver of health IT value. Furthermore, hospital adoption of health IT could affect neighboring providers IT adoption and IT value either directly or indirectly. We test for the presence of network externalities in health IT productivity using a similar identification strategy to Gowrisankaran and Stavins (2004) in which fixed-effects control for unobserved heterogeneity that affect the firms' and neighbors' adoption. We further employ instrumental variables in a DPD framework to address time-varying sources of endogeneity.

To implement the test for network externalities, we construct measures of neighboring hospitals IT input use. For each hospital, local markets are defined as other hospital institutions in a 30-mile radius. ${ }^{14}$ Market-level IT input utilization measures are based on neighboring hospitals' average IT capital and IT labor inputs. These measures are weighted by the number of staffed inpatient beds. These variables are then added to the the base specification and treated as potentially productive inputs. Neighbors' IT inputs are also

\footnotetext{
${ }^{14}$ We have also examined the robustness of our results using alternative radii. The results are robust to these different measures. Market areas were constructed using batchgeo's geocoding service and confirmed via USC WebGIS Services (Goldberg and Wilson, 2010).
} 
considered potentially endogenous.

Health IT value may also change over time. Technological innovation could, for example, increase the value of more recent IT investments. This may be particularly important as innovation spurred the rapid diffusion of EMR and CPOE systems during our study period. Conversely, learning may increase the value of older IT investments as hospitals train staff or adjust work flows when implementing new information systems. We employ several approaches to explore these issues. First, we divide the data into pre- and post-2002 subsamples and estimate parameters for each period separately. We also estimate models that allow for higher-order autocorrelation in the IT inputs. In addition, larger hospitals may utilize health IT more effectively as the benefits of managing large amounts of patient data plausibly increases in the size of the hospital. In order to examine this possibility, we divide the sample in half based on hospital bed size (median $=173$ beds) and estimate the production function parameters separately for each group of hospitals.

\section{Data}

Our primary source is the Office of Statewide Health Planning and Development (OSHPD) data from 1997 to 2007. These data contain detailed annual financial and productivity information for the vast majority of California hospitals. They also contain hospital characteristics such as bed size and ownership. We supplement these data with the Health Information Systems Society (HIMSS) Analytic survey from 1998-2007. The HIMSS data contain detailed information on the specific applications adopted by hospitals. The HIMSS data serve as a window into the specific IT strategies that hospitals employ.

Our sample comprises 309 short-term, acute care, non-federal, California hospitals. The Kaiser Permanente hospitals are excluded as they do not report detailed hospital-level financial data to OSHPD. ${ }^{15}$ The OSHPD data include detail balance sheet, income statement, and other financial as well as non-financial information. ${ }^{16}$ Hospitals are required by California

\footnotetext{
${ }^{15}$ These sixteen Kaiser hospitals are part of a vertically integrated managed care organization that includes a health plans, employed physicians, and other health care providers; consequently, they were exempted from the reporting requirements faced by other hospitals.

${ }^{16}$ There were a modest number of missing values which were imputed via hot deck and stratified by bed
} 
law to report this information and OSHPD make these data publicly available. ${ }^{17}$ We operationalize our output measure, value-added, as operating revenues less intermediate inputs. Conventional (non-IT) capital is defined as total assets, including: current assets, property, plant and equipment, intangible assets, assets whose use is limited, and other assets. Naturally, IT capital inputs were excluded from the measure of conventional capital. Conventional (non-IT) labor is defined as the total conventional salaries, wages, employee benefits, and professional fees. ${ }^{18}$

A unique aspect of the OSHPD data is that it tracks hospital IT expenditures by input category. That is, we can formulate measures of both IT capital and labor. ${ }^{19}$ The OSHPD data place all IT expenditures within financial statements' data processing sections. For our purposes, information technology labor is the summation of salaries and wages, employee benefits, and professional fees associated with data processing. Information technology capital is a summation of four components: purchased services, leases and rentals, other direct expenditure, and physical capital respectively. Lease and rentals represent IT capital such as software licensing payments. Purchased services are payment for outsourced IT such as application service provision. ${ }^{20}$ Physical capital is the quantity of IT capital stock at a specific time whereas the previous three categories are flow measures. A complication of the construction of health IT capital is that OSHPD does not directly report the stock of physical IT capital but only reports flow expenditures on IT capital in each given year. We therefore construct the stock of health IT physical capital using the reported IT investments. The Modified Accelerated Cost Recovery System (MACRS) specifies that computers and information systems are depreciated over a five-year period. ${ }^{21}$ We use a 5-year linear deprecation

\footnotetext{
size and ownership type.

${ }^{17}$ The data are available at http://www.oshpd.ca.gov/HID/DataFlow/HospFinancial.html.

${ }^{18}$ Our measure of labor inputs also include the labor intensive inputs of ancillary services, research, education, general services, fiscal services, and administrative services.

${ }^{19}$ Many data sets used to study the firm-level impact of IT lack information on either IT labor expenditures or, more importantly, IT capital.

${ }^{20}$ We recognize that purchased services likely include both capital and labor inputs. While the data do not provide the detail necessary to disentangle the component inputs qualitative work suggests that this is mostly a capital measure.

${ }^{21}$ Economic depreciation of IT assets would be better described as a capital loss due to technological obsolescence and is likely more rapid (e.g., over four years).
} 
schedule in order to construct the annual physical IT capital stock for each hospital in our data. $^{22}$ Our IT input measures were confirmed with data from HIMSS, which occasionally included analogous questions within their survey.

\section{Trends and Summary Statistics in Health IT adop- tion}

Figure 1 displays the trends in IT capital stock and IT labor inputs per bed for our sample of hospitals. Information technology capital and labor inputs increased steadily from 1997-2007. Over this time frame IT capital stock grew almost three-fold to over $\$ 35,000$ per staffed bed in 2007. The employment of IT labor also grew but less rapidly than IT capital. Between 1997 and 2007, on average, hospitals' IT labor inputs more than doubled.

Descriptive statistics are provided in Table 1 . The mean values of $Y_{i t}, L_{i t}, K_{i t}, L_{i t}^{c}$, and $K_{i t}^{c}$ are provided in both levels and shares relative to value-added. ${ }^{23}$ Several patterns in the summary statistics are worth highlighting. First, health IT capital inputs increased dramatically over this period, both in absolute and relative terms. Average health IT capital grew $220 \%$ and as a percentage of value-added grew from $3.6 \%$ to $4.5 \%$. Information technology labor inputs grew $213 \%$ over this period and its share relative to value-added increased marginally.

Not-for-profit hospitals constitute $55 \%$ of the sample while for-profit and governmentowned hospitals comprise $25 \%$ and 20\%, respectively. On average, FP hospitals are significantly smaller than NFP and government hospitals. There are also meaningful differences across ownership forms in the use of health IT. For-profit hospitals utilize less IT inputs but more conventional capital per dollar of output than NFP hospitals. The relative growth rate of health IT capital for FPs is also notably lower than NFP hospitals. This suggests that either FPs have different production technologies than NFPs, that they face different input costs or that they have different objectives in their health IT utilization.

The HIMSS data allow to us examine the patterns of health IT adoption across EMR and

\footnotetext{
${ }^{22}$ We use data from the years 1993 to 1996 to calculate the initial period IT capital stock.

${ }^{23}$ The variables are converted to 2007 dollars using the GDP deflater.
} 
CPOE - two important health IT components that were diffusing during our time period. Figure 2 displays the time series of the percentage of hospitals that have adopted these platforms for the entire sample and separately for NFP, FP, and government hospitals. The figure shows that the increases in IT capital are associated with increased adoption of these two technologies. That is, the expansion of health IT capital reflects (at least in part) the adoption of these technologies. Over this time frame, EMR diffused much more widely than CPOE. By 2007, almost 50\% of hospitals had adopted EMR while approximately $33 \%$ of hospitals had adopted CPOE. There are meaningfully different patterns of technology adoption between NFP and FP hospitals. FP hospitals began the period with a much lower EMR adoption rate but by the end of the sample they slightly higher EMR utilization levels. FP hospitals, however, continued to lag other hospitals in the adoption of more sophisticated systems with CPOE capabilities. These figures and the summary statistics suggest that, in fact, FP and NFP hospital may have divergent strategic aims in their use of health IT. Our measure of EMR differs notable from Jha et al. (2009) as they focus on comprehensive electronic health record systems and is more similar to the enterprise EMR studied by Tucker and Miller (2011). While the HIMSS data demonstrate that clinically relevant information systems are rapidly diffusing during our study period, it is not practical to employ the these data directly in our analysis. ${ }^{24}$

Production function parameters are identified by dynamic variation in the input choices (Ackerberg et al., 2006b; Bond and Soderbom, 2005). The variation we leverage to identify the parameters is demonstrated by the means and standard deviations in the logarithm of the hospital-specific, long difference $(t=2007$ minus $t=1997)$. The mean of the difference in the logarithms of the inputs is .88, .53, .80 and 1.15 and the standard deviations are .35, $.65,1.20$ and 1.20 for $L, K, L^{c}$, and $K^{c}$ respectively. There is notable heterogeneity in input utilization for all the inputs over this period.

\footnotetext{
${ }^{24}$ The discrete nature of the HIMSS application data cannot, for example, be incorporated into the OP, LP, or ACF models as the function could not be inverted. While discrete data can, in theory, be employed in the DPD models there is only meaningful variation during the year of actual technology adoption. Finally, the detailed application-level data are not available for all years of our sample.
} 


\section{Production Function Results}

The production function estimates are presented in Table 2. The first two columns present OLS and FE estimates. Parameter estimates from the DPD model are presented in column (3). The OLS and FE model estimates are almost all lower than the estimates in our base model. This is consistent with the large literature estimating production function parameters and the notion that input choices are endogenous. The DPD estimates indicate that IT capital and IT labor are very productive and the coefficients are significantly different from zero. The common factor restrictions are not rejected for the DPD model (they are for the OLS and FE estimates), and the Hanson test p-value is .54 indicating that the over identification restrictions are not rejected. The parameter estimates also do not reject a constant returns to scale technology. That is, the standard tests do not reject the DPD specification.

The ACF, OP and LP estimates are reported in columns (4), (5), and (6) of Table 2 respectively. ${ }^{25}$ Parameter estimates from these models are, generally, lower than the estimates from the DPD approach but still higher than the OLS and FE estimates; furthermore, the standard error bands for the DPD, ACF, OP, and LP models generally overlap. Interestingly, the ACF, OP and LP parameter estimates for the IT variables are all very similar, however there are important differences across approaches in the parameters on the conventional inputs. For example, the OP estimates imply increasing returns to scale while the ACF and LP estimates are consistent with constant returns to scale. While broadly consistent with the $\mathrm{ACF} / \mathrm{LP} / \mathrm{OP}$ estimates, the dynamic panel data model generates higher health IT elasticities and may be seen as an upper bound of our parameter estimates.

\subsection{Contributions of health IT to value-added}

We examine the implications of our production function parameter estimates on the historical contributions of hospitals' IT inputs to value-added and the forecasted impact of the broad health IT expansion contained in the HITECH act. To measure the historical contribution

\footnotetext{
${ }^{25}$ Standard errors for the ACF, OP and LP models are generated via bootstrap using 200 draws.
} 
of health IT, we calculate the difference in each hospital's implied value-added under 2007 and 1997 health IT input levels. Value-added grew an average of $156 \%$ over this period - an approximately $7 \%$ compound growth rate. Health IT capital grew an average of $220 \%$ over this period while IT labor grew by $213 \%$. Combined, IT inputs accounted for a $6 \%$ increase in value added output.

We use our parameter estimates to model the implied long-run net benefits of expanding IT inputs. The IT capital marginal product calculations depend on hospitals' opportunity cost of capital and on the rate of IT capital depreciation. We assume a nine percent opportunity cost of capital and four-year straight-line depreciation for IT capital inputs. ${ }^{26} \mathrm{We}$ first recovered hospital-specific productivity shocks, $\epsilon_{i t}$. Counterfactual simulations were the based on parameter estimates and actual input levels.

All estimation strategies yield high marginal products for IT capital inputs. These range from $\$ 0.73$ (95\% CI: $\$ 0.33$ to $\$ 1.42$ ) for ACF to $\$ 1.29$ (95\% CI: $\$ 0.48$ to $\$ 2.22)$ for DPD. The net marginal product of IT labor ranges from $\$ 0.006$ (95\% CI: $\$-0.22$ to $\$ 0.37$ ) for ACF to $\$ 1.45$ (95\% CI: $\$ 0.33-\$ 2.65$ ) for DPD. The implied IT labor marginal products for OP and LP were negative but not statistically significant. These marginal products are similar to estimates of IT value in other industries. For example, Brynjolfsson and Hitt (1996) estimate a net marginal product of $\$ 1.62$ for IT labor and a long-run net marginal product of $\$ 0.67$ for IT capital.

While the marginal effects of IT inputs are high, their absolute contribution to valueadded is modest. Both IT inputs exhibit high marginal benefits that diminish slowly. These results suggest that substantial increases in IT inputs would be beneficial. Doubling IT capital inputs from 2007 levels would increase total value added by less than $2 \%$ while doubling IT labor inputs would increase value added by less than $1 \%$ for the median hospital.

The high marginal products for health IT could reflect either an underinvestment in IT or the cost of unmeasured complements. For example, Brynjolfsson and Hitt (2003) find

\footnotetext{
${ }^{26}$ Outsourced IT goods and services are treated as flow inputs. We reach similar conclusions when varying the cost of capital or depreciating IT capital over a five-year period. We also explore alternative models that estimate separate parameters for owned and outsourced IT. Our overall policy conclusions are consistent with these alternative assumptions.
} 
that IT investments are correlated with MFP. This could be because software expenditures (a large share of total IT costs) are not observed in their data or the cost of unobserved organizational investments.

We perform several robustness tests for bias due to unobserved complementary inputs. First, organizational complements, such as works-flow reorganization and changes in job design would likely lag IT capital investments, leading to vintage effects. Second, complementary organizational investments may play a bigger role for large IT investments. Finally, unobserved complements would likely lead to a correlation between IT investments and MFP. We find no evidence of vintage effects (see below) and no evidence that IT value differed for small or large investments.

We calculate the change in MFP over 1997-2007 using our parameter estimates. The weighted (by 2007 value-added) average percent change in hospital MFP over this period is $2.0 \%$ and the standard deviation is $18.2 \%{ }^{27}$ There was virtually no change in the average MFP across hospitals, and there is little difference in the change in MFP across NFP and FP hospitals (approximately 4.5\%). However, government hospitals saw a significant decline in MFP of $5.6 \%$. We find no correlation between IT inputs and MFP.

These results further imply that the vast majority of the increase in hospital valueadded over this period is directly tied to the expansion of hospitals' capital and labor inputs. These findings align with Cutler (2010) who contends that, unlike most other industries, the necessary forces are not in place to drive changes in organizational productivity in health care delivery.

\subsection{Organizational differences, network externalities and vintage effects}

Table 3 presents production function estimates by hospital ownership form. ${ }^{28}$ Hospital ownership may play an important role in their organizational objectives and may influence investment behavior (Sloan, 2000; Horowitz and Nichols, 2009; David et al., 2011). While we

\footnotetext{
${ }^{27}$ Unweighted means and standard deviations yield similar conclusions.

${ }^{28} \mathrm{ACF}$ parameter estimates for specifications discuss in this section are presented in the Appendix. These estimates do not materially affect our conclusions.
} 
cannot directly incorporate these heterogeneous hospital preferences into our model, we can estimate the model dividing the sample according to ownership status. These results are reported in the first three columns of Table 5. Although the health IT parameter estimates differ across ownership structures, the standard errors are large enough that we cannot reject that the coefficients for NFP, FP and government hospitals are equal. That being said, because FP hospitals invest significantly less in health IT capital, the implied marginal product is much higher than for other hospitals. These results combined with the evidence presented above suggest that FP hospitals invest differently in health IT.

Table 3 also presents our estimates of the impact of network effects on health IT productivity in column (4). Parameter estimates for $l_{-i, t}^{c}$ and $k_{-i, t}^{c}$, which measure the effect of neighbors' health IT inputs, are close to zero, statistically insignificant, and precisely estimated. That is, we find no evidence of network externalities. This is not surprising. As discussed in Section 2, these technologies are not usually inter-operable across hospitals and, in general, hospitals do not exchange information with each other. The policy implication is that network externalities do not cause sub-optimal levels of IT adoption.

We also examined whether there is meaningful heterogeneity in the impact of health IT on value-added. To do this, we split the sample in half based on the number of staffed beds and estimate the parameters for each sample. Table 4, columns (1) and (2) presents the results from this exercise. Parameter estimates indicate that there is virtually no significant difference in health IT parameters across samples; however, there are differences in the other parameters. While the coefficients are all significantly different from zero, the standard errors are large enough that the estimates may not distinguish modest differences in parameters across hospital categories.

Our data cover a significant span of time during which improvements in productivity of health IT likely occurred. ${ }^{29}$ Rapid innovation would lead us to underestimate the impact of future health IT investments. Therefore, we tested for vintage effects by examining whether the output elasticity of health IT increased over our study period. We divided the data

\footnotetext{
${ }^{29}$ Discussions with industry experts point to meaningful improvements in the functionality of health IT over this period.
} 
into two samples based on the year of the observation. The samples periods are 1997-2001 and 2002-2007. Table 4 also presents the production function parameter estimates for these two samples. The estimates suggest that, in fact, health IT became more productive over time. The health IT labor parameter, in particular, is larger in the 2002-2007 period and significantly different from the 1997-2001 period parameter (which is close to zero). The IT capital parameter is also larger in later period but the differences are not significant. While the parameters are larger in the later period the economic implications of these differences is modest and does not materially affect our conclusions regarding the impact of health IT expansions on value-added. Alternative specifications allowed the effects of IT inputs to change after their adoption. Changes could capture either learning or innovation effects. These effects were small in magnitude and not significantly different from 0.

\subsection{Alternative Specifications}

The Cobb-Douglas specification imposes strong functional assumptions on output elasticities and marginal productivity. We thus estimated a series of more flexible specification. These models incorporated interactions between IT inputs and other inputs as well as higher order terms of IT inputs. These terms were incorporated into the models individually. These additional parameters were never statistically significant and the overall model results were similar to those reported above. We also incorporated these changes simultaneously using a translog specification. Translog models fit the data poorly and parameter estimates were neither significant nor coherent. The poor fit is unsurprising given our relatively small sample size. Furthermore, other studies of IT and productivity have had similar difficulties in employing more flexible specifications (Brynjolfsson and Hitt, 1996, 2003; Tambe and Hitt, 2010). Thus, we find little convincing evidence indicating that our results are driven by the Cobb-Douglas assumption or that health IT has a more complex (and perhaps more interesting) impact on value-added than implied by the Cobb-Douglas production function. 


\section{Conclusion}

We study the effect of IT capital and labor on productivity. We employ a variety of identification strategies as hospitals' IT investments are both persistent and endogenous. Naive identification strategies underestimate the effect of IT on productivity, suggesting that IT investments are correlated with negative productivity shocks. These shocks may include unobserved quality or patient severity.

Hospitals' IT investments are highly productive at the margin. The median long-run net marginal products of IT inputs are $\$ 1.04$ for IT capital and $\$ 0.73$ for IT labor. We find that the value of increased IT inputs diminishes slowly and that inputs are complementary (consistent with the Cobb-Douglas constant elasticity of substitution assumption). Health IT's high marginal product suggests that widespread adoption may generate large productivity gains. While the marginal benefits are high, IT represents a small share of total inputs and the absolute benefits are modest. Doubling IT capital inputs would increase total valueadded by less than $2 \%$. These findings suggest that federal initiatives aimed at increasing IT investments may lead to efficiencies, but they are unlikely to transform health care delivery.

These high marginal products raise interesting questions about the efficiency of IT adoption. In equilibrium, hospitals should employ inputs until their long-run net marginal products are $\$ 0$. An important limitation of our study is that we do not observe complementary organizational inputs such as training or work-flow reorganization. Complementary input costs could lead us to overestimate the marginal products of IT inputs. While unobserved complements certainly matter, we perform a series of robustness tests that suggest the magnitude of such bias is small.

Our findings suggest that IT inputs are, at the margin, under-utilized. Several mechanisms could lead to underinvestment in health IT. With a rapidly changing technology, there may be imperfect information or uncertainty regarding the costs and benefits of investment. This uncertainty may be important as Song et al. (2011) find that even sophisticated health care systems have made no attempt to calculate the return on IT investments and the empirical literature provides few insights into this question. Furthermore, hospitals (particularly 
not-for-profit institutions) often lack access to capital markets. The high marginal products could also reflect shortages in skilled IT labor in the California market, either for hospitals or health IT vendors. Under these conditions, adoption subsidies would be welfare enhancing.

We also consider the possibility that health IT's value depends on network externalities. For example, neighboring providers' use of interoperable medical records systems could increase the value of health IT investments. Alternatively, provider and staff learning could lead to indirect network effects. We test this issue directly and find no evidence of network externalities. However, we recognize that comprehensive electronic health records systems are rare (Jha et al., 2009) and direct network effects may be realized in the future as more sophisticated IT systems are widely adopted.

Health IT utilization differs substantially by hospital ownership. For-profit hospitals utilize $83 \%$ less IT capital than not-for-profit hospitals. For-profit institutions also utilize more IT labor per dollar of IT capital. We find that the marginal products of IT inputs are higher in for-profit institutions. Application level-data indicate that for-profit institutions lag their non-profit peers in the adoption of potentially quality-enhancing systems. These findings suggests that ownership structures affect hospitals health IT adoption strategies.

One important limitation of our study is that we do not directly observe quality. While this should not bias our estimates of IT and value-added, we may underestimate the total welfare gains from health IT investments. Although this is an important issue, recent studies suggest that this problem is quite small for the average hospital (e.g., (McCullough et al., 2010; Agha, 2011; McCullough et al., 2011; Tucker and Miller, 2011)). Furthermore, IT forms a small share of hospitals' total inputs while exhibiting lower marginal products than observed in other service industries (Tambe and Hitt, 2010). 


\section{References}

Acemoglu, D. and Finkelstein, A. (2008). Input and technology choices in regulated industries: Evidence from the health care sector. The Journal of Political Economy, 116:837-880.

Ackerberg, D., Benkard, L., Berry, S., and Pakes, A. (2006a). Econometric tools for analyzing market outcomes. Forthcoming, Handbook of Econometrics.

Ackerberg, D., Caves, K., and Frazer, G. (2006b). Structural identification of production functions.

Agha, L. (2011). The effects of health information technology on costs and quality of medical care. Working paper.

Arellano, M. and Bond, S. (1991). Some tests of specification for panel data: Monte carlo evidence and an application to employment equations. The Review of Economic Studies, 58:277-297.

Arellano, M. and Bover, O. (1995). Another look at the instrumental-variable estimation of error-components models. Journal of Econometrics, 68:29-52.

ARRA (2009). American Reinvestment and Recovery Act. 111-5 Public Law.

Athey, S. and Stern, S. (2002). The impact of information technology on emergency health care outcomes. Rand Journal of Economics, 33:399-432.

Bartel, A., Ichniowki, C., and Shaw, K. (2007). How does information technology affect productivity? Plant-level comparisons of product innovation, process improvement, and worker skills. Quarterly Journal of Economics, 122:1721-1758.

Black, A., Car, J., Pagliari, C., Anandan, C., Cresswell, K., Bokun, T., McKinstry, B., Procter, R., Majeed, A., and Sheikh, A. (2011). The impact of ehealth on the quality and safety of health care: A systematic overview. PLos Med, 8. 
Bloom, N., Sadum, R., and Reenen, J. V. (2012). Americans do it better: Us multinationals and the productivity miracle. American Economic Review. Forthcoming.

Blundell, R. and Bond, S. (1998). Initial conditions and moment restrictions in dynamic panel data models. Journal of Econometrics, 87:115-143.

Blundell, R. and Bond, S. (2000). Gmm estimation with persistent panel data: an application to production functions. Econometric Reviews, 19:321-340.

Bond, S. and Soderbom, M. (2005). Adjustment costs and the identification of cobb-douglas production functions. Oxford University Working Paper.

Borzekowski, R. (2009). Measuring the cost impact of hospital information systems: 19871994. Journal of Health Economics, 28:938-949.

Brynjolfsson, E. and Hitt, L. (1996). Paradox lost? firm-level evidence on the returns to information systems. Management Science, 42(4):541-558.

Brynjolfsson, E. and Hitt, L. (2003). Computing productivity: Firm-level evidence. The Review of Economics and Statistics, 85:793-808.

Buntin, M., Burke, M., Hoaglin, M., and Blumenthal, D. (2011). The benefits of health information technology: A review of the recent literature shows predominantly positive results. Health Affairs, 30:464-471.

Collen, M. (1995). A history of medical informatics in the united states.

Culter, D., Huckman, R., and Landrum, M. (2004). The role of information in medical markets: An analysis of publicly reported outcomes in cardiac surgery. The American Economic Review, 95:342-346.

Cutler, D. (2010). Where are the health care entrepreneurs? Issues in Science and Technology, 27:49-56. 
Cutler, D. M. (2004). Your Money or Your Life: Strong Medicine for America's Health Care System. Oxford University Press, New York.

David, G., Lindrooth, R., Helmchen, L., and Burns, L. R. (2011). Do hospitals cross subsidize? NBER working paper 17300.

Goldberg, D. and Wilson, J. (2010). USC WebGIS Services. Available online at https://webgis.usc.edu.

Gowrisankaran, G. and Stavins, J. (2004). Network externalities and technology adoption: lessons from electronic payments. RAND Journal of Economics, 35:260-276.

Hillestad, R., Bigelow, J., Bower, A., Girosi, F., Meili, R., Scoville, R., and Taylor, R. (2005). Can electronic medical record systems transform health care? potential health benefits, savings, and costs. Health Affairs, 24:1103-1117.

Hitt, L. (2010). The effect of it capital on hospital efficiency. Management Science.

Horowitz, J. and Nichols, A. (2009). Hospital ownership and medical services: Market mix, spillover effects, and nonprofit objectives. Journal of Health Economics, 28:924-37.

Institute of Medicine (1999). To Err Is Human: Building a Safer Health System. National Academy Press, Washington, DC.

Institute of Medicine (2001). Crossing the Quality Chasm: A New Health System for the 21st Century. National Academy Press, Washington, DC.

Institute of Medicine (2003). Unequal Treatment: Confronting Racial and Ethnic Disparities in Health Care. National Academy Press, Washington, DC.

Jha, A., DesRoches, C., Cambell, E., Donelan, K., Rao, S., Ferris, T., Shields, A., Rosenbaum, S., and Blumenthal, D. (2009). Use of electronic health records in u.s. hospitals. The New England Journal of Medicine, 360:1628-1638. 
Jha, A., Doolan, D., Grandt, D., Scott, T., and Bates, D. (2008). The use of health information technology in seven nations. International Journal of Medical Informatics, 77:848-854.

Katz, M. and Shapiro, C. (1986). Technology adoption in the presence of network externalities. Journal of Political Economy, 94:822-841.

Lapointe, L., Mignerate, M., and Vedel, I. (2011). The it productivity paradox in health: A state holder's perspective. International Journal of Medical Informatics, 80:102-115.

Levinsohn, J. and Petrin, A. (2003). Estimating production functions using inputs to control for unobservables. Review of Economic Studies, 70:317-341.

Marschak, J. and Andrews, W. (1944). Random simultaneous equations and the theory of production. Econometrica, 12:143-205.

McCullough, J. (2008). The adoption of health information systems. Health Economics, 17:649-664.

McCullough, J., Casey, M., Moscovice, I., and Prasad, S. (2010). The effect of health information technology on quality in us hospitals. Health Affairs, 29:647-654.

McCullough, J., Parente, S., and Town, R. (2011). The impact of health it adoption on the quality of patient care. Working paper.

Olley, S. and Pakes, A. (1996). The dynamics of productivity in the telecommunications equipment industry. Econometrica, 64:1263-1298.

Parente, S. and Horn, R. V. (2007). Valuing hospital investment in information technology: Does governance make a difference? Health Care Financing Review, 28(2):31-43.

Sloan, F. (2000). Not-for-profit ownership and hospital behavior. In Culyer, A. and Newhouse, J., editors, Handbook of Health Economics, Vol 1B. Elsevier B.V, Amsterdam.

Song, P., McAlarney, A., Robbins, J., and McCullough, J. (2011). Exploring the business case for ambulatory electronic health record system adoption. Journal of Healthcare Management, 56:169-180. 
Stiroh, K. (2002). Information technology and the us productivity revival: What do the industry data say? American Economic Review, 92:1559-1576.

Tambe, P. and Hitt, L. (2010). The productivity of information technology investments, 1987-2006. NYU Working Paper.

Tucker, C. and Miller, A. (2011). Can healthcare IT save babies? Journal of Political Economy, 119:289-324. 
Figure 1: Trends in IT capital and IT labor per bed

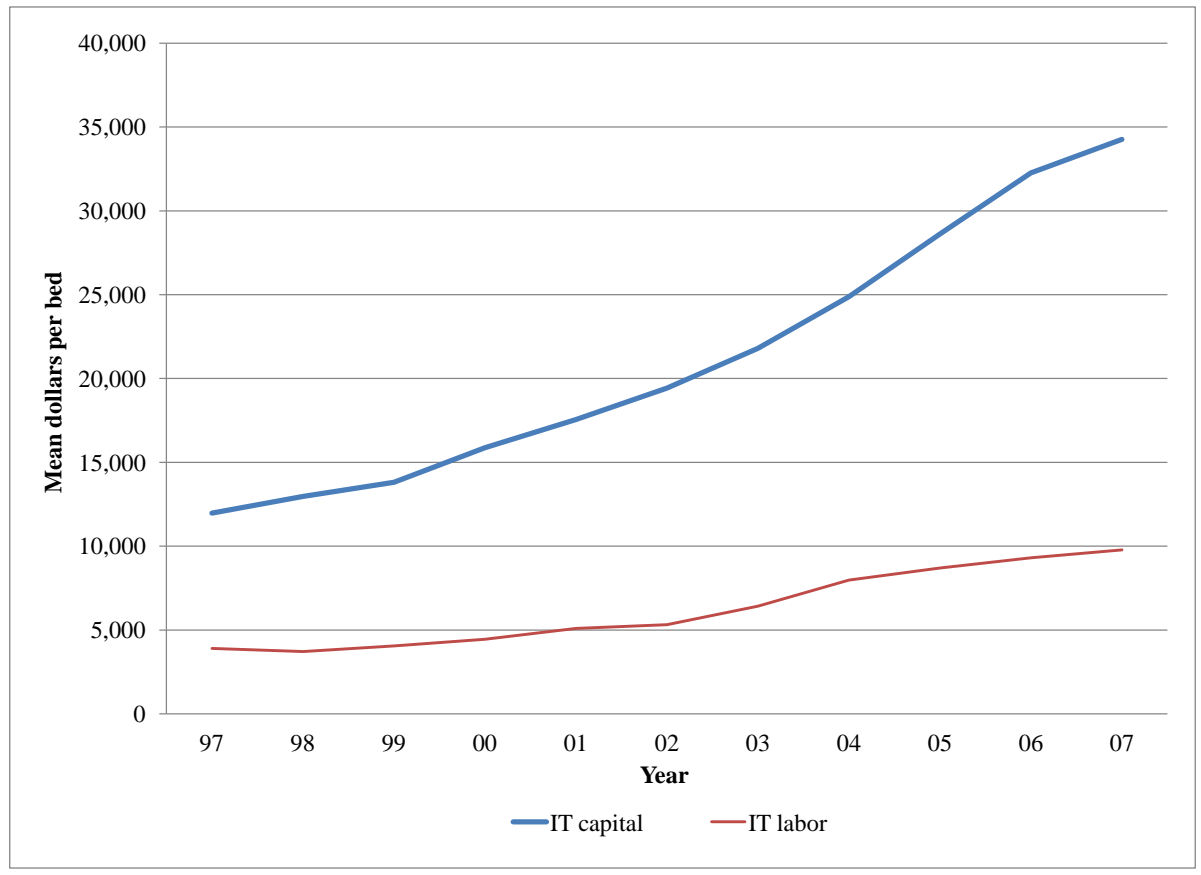


Figure 2: Trends in EMR and CPOE adoption

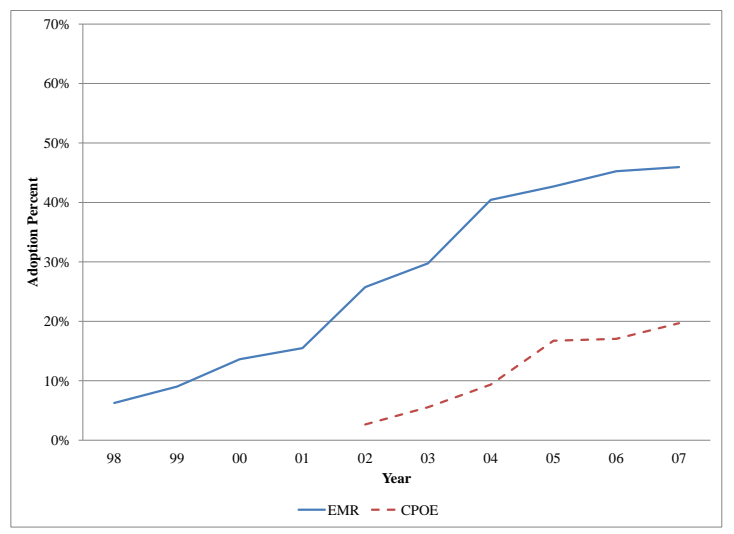

All Hospitals

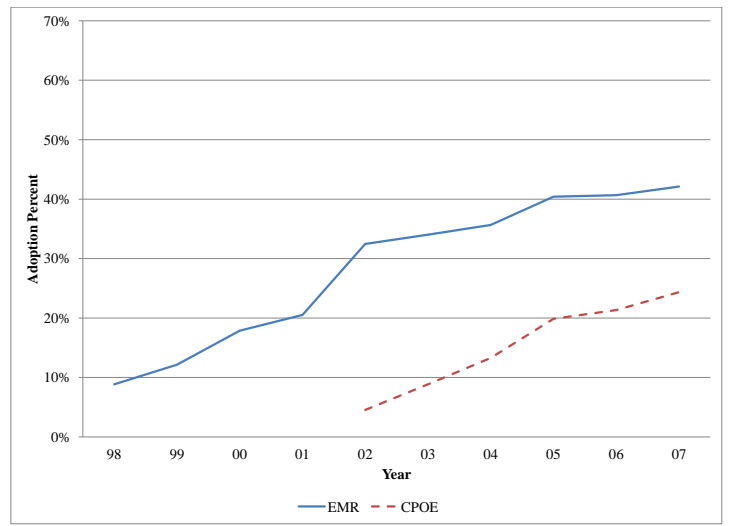

Not-For-Profit

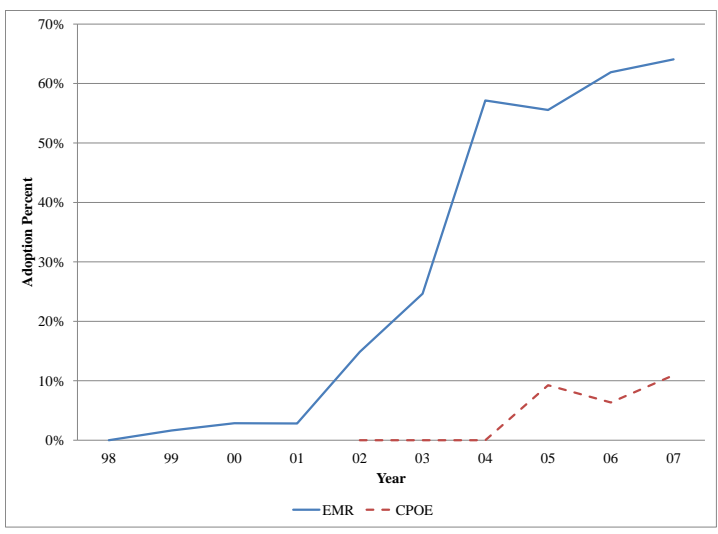

For-profit

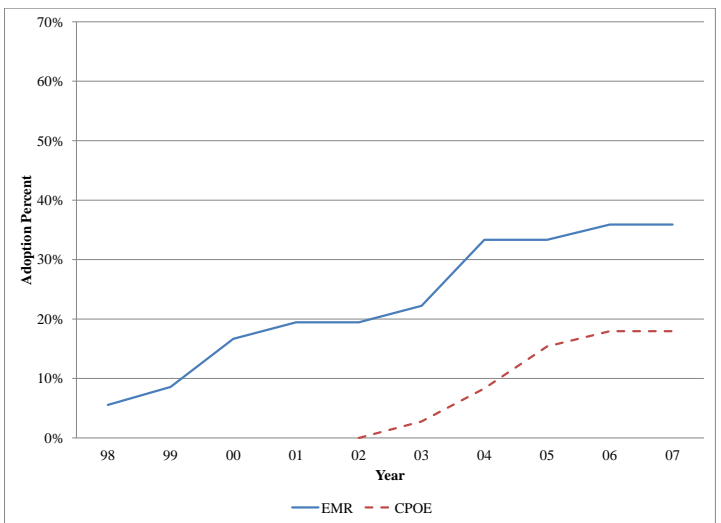

Government 
Table 1: Means and (std. dev.) in $\$ 1,000$ and shares of input as a $\%$ of value-added

\begin{tabular}{|c|c|c|c|c|c|c|c|c|}
\hline \multicolumn{9}{|c|}{ Entire Sample } \\
\hline Variable & Total & Share & $F P$ & Share & $N F P$ & Share & Gov. & Share \\
\hline Value added $(Y)$ & $\begin{array}{r}133,895 \\
(181,806)\end{array}$ & $100.0 \%$ & $\begin{array}{r}74,892 \\
(71,881)\end{array}$ & $100.0 \%$ & $\begin{array}{r}164,548 \\
(208,531)\end{array}$ & $100.0 \%$ & $\begin{array}{r}124,326 \\
(180,735)\end{array}$ & $100.0 \%$ \\
\hline Labor $(L)$ & $\begin{array}{r}117,851 \\
(151,530)\end{array}$ & $88.0 \%$ & $\begin{array}{r}67,161 \\
(60,158)\end{array}$ & $89.7 \%$ & $\begin{array}{r}145,031 \\
(173,742)\end{array}$ & $88.0 \%$ & $\begin{array}{c}107,389 \\
(149,212)\end{array}$ & $86.4 \%$ \\
\hline Capital $(K)$ & $\begin{array}{r}173,090 \\
(267,923)\end{array}$ & $129.3 \%$ & $\begin{array}{r}81,171 \\
(120,701)\end{array}$ & $108.4 \%$ & $\begin{array}{r}219,832 \\
(2314,255)\end{array}$ & $133.6 \%$ & $\begin{array}{c}150,844 \\
(234,095)\end{array}$ & $121.3 \%$ \\
\hline IT Labor $\left(L^{c}\right)$ & $\begin{array}{r}1,576 \\
(3,146)\end{array}$ & $1.2 \%$ & $\begin{array}{r}539 \\
(903)\end{array}$ & $0.7 \%$ & $\begin{array}{r}2,025 \\
(3,793)\end{array}$ & $1.2 \%$ & $\begin{array}{c}1,616 \\
(2,678)\end{array}$ & $1.4 \%$ \\
\hline IT Capital $\left(K^{c}\right)$ & $\begin{array}{r}5,537 \\
(11,206)\end{array}$ & $4.1 \%$ & $\begin{array}{r}1,306 \\
(1,757)\end{array}$ & $1.7 \%$ & $\begin{array}{r}7,823 \\
(13,866)\end{array}$ & $4.8 \%$ & $\begin{array}{c}4,609 \\
(7,723)\end{array}$ & $3.7 \%$ \\
\hline Number of Hospitals & 309 & & 78 & & 169 & & 62 & \\
\hline \multicolumn{9}{|c|}{1997} \\
\hline Value added $(Y)$ & $\begin{array}{r}83,889 \\
(109,648)\end{array}$ & $100.0 \%$ & $\begin{array}{r}35,110 \\
(29,756)\end{array}$ & $100.0 \%$ & $\begin{array}{r}101,514 \\
(110,840)\end{array}$ & $100.0 \%$ & $\begin{array}{r}81,528 \\
(134,698)\end{array}$ & $100.0 \%$ \\
\hline Labor $(L)$ & $\begin{array}{r}72,889 \\
(86,476)\end{array}$ & $90.5 \%$ & $\begin{array}{r}34,221 \\
(30,292)\end{array}$ & $97.5 \%$ & $\begin{array}{r}88,836 \\
(89,668)\end{array}$ & $87.5 \%$ & $\begin{array}{r}66,237 \\
(99,023)\end{array}$ & $81.2 \%$ \\
\hline Capital $(K)$ & $\begin{array}{r}115,968 \\
(1452,400)\end{array}$ & $131.3 \%$ & $\begin{array}{r}38,218 \\
(41,421)\end{array}$ & $108.9 \%$ & $\begin{array}{r}150,970 \\
(172,165)\end{array}$ & $148.7 \%$ & $\begin{array}{r}95,479 \\
(132,141)\end{array}$ & $117.1 \%$ \\
\hline IT Labor $\left(L^{c}\right)$ & $\begin{array}{r}867 \\
(943)\end{array}$ & $1.0 \%$ & $\begin{array}{r}247 \\
(268)\end{array}$ & $0.7 \%$ & $\begin{array}{r}1,108 \\
(2,027)\end{array}$ & $1.1 \%$ & $\begin{array}{r}793 \\
(1,228)\end{array}$ & $1.0 \%$ \\
\hline IT Capital $\left(K^{c}\right)$ & $\begin{array}{r}3,013 \\
(5,239)\end{array}$ & $3.6 \%$ & $\begin{array}{r}715 \\
(1,123)\end{array}$ & $2.0 \%$ & $\begin{array}{r}4,156 \\
(6,371)\end{array}$ & $4.1 \%$ & $\begin{array}{r}2,145 \\
(3,058)\end{array}$ & $2.6 \%$ \\
\hline Number of Hospitals & 293 & & 57 & & 167 & & 69 & \\
\hline \multicolumn{9}{|c|}{2007} \\
\hline Value added $(Y)$ & $\begin{array}{r}214,317 \\
(262,092)\end{array}$ & $100.0 \%$ & $\begin{array}{c}115,876 \\
(92,247)\end{array}$ & $100.0 \%$ & $\begin{array}{r}281,136 \\
(316,109)\end{array}$ & $100.0 \%$ & $\begin{array}{r}159,184 \\
(186.868)\end{array}$ & $100.0 \%$ \\
\hline Labor $(L)$ & $\begin{array}{r}193,456 \\
(223,600)\end{array}$ & $90.3 \%$ & $\begin{array}{r}109,684 \\
(81,550)\end{array}$ & $94.7 \%$ & $\begin{array}{r}241,869 \\
(257,135)\end{array}$ & $86.0 \%$ & $\begin{array}{r}168,901 \\
(215,093)\end{array}$ & $106.1 \%$ \\
\hline Capital $(K)$ & $\begin{array}{r}291,573 \\
(438,564)\end{array}$ & $136.0 \%$ & $\begin{array}{r}126,601 \\
(176,743)\end{array}$ & $109.3 \%$ & $\begin{array}{r}390,184 \\
(431,344)\end{array}$ & $138.8 \%$ & $\begin{array}{r}233,344 \\
(351,288)\end{array}$ & $146.6 \%$ \\
\hline IT Labor $\left(L^{c}\right)$ & $\begin{array}{r}2,712 \\
(5,140)\end{array}$ & $1.3 \%$ & $\begin{array}{r}914 \\
(1,516)\end{array}$ & $0.8 \%$ & $\begin{array}{r}3,507 \\
(56,159)\end{array}$ & $1.2 \%$ & $\begin{array}{r}2,794 \\
(4,519)\end{array}$ & $2.1 \%$ \\
\hline IT Capital $\left(K^{c}\right)$ & $\begin{array}{r}9,630 \\
(18,131)\end{array}$ & $4.5 \%$ & $\begin{array}{r}2,333 \\
(2,550)\end{array}$ & $2.0 \%$ & $\begin{array}{r}14,191 \\
(22,709)\end{array}$ & $5.0 \%$ & $\begin{array}{r}6,543 \\
(10,439)\end{array}$ & $4.1 \%$ \\
\hline Number of Hospitals & 298 & & 74 & & 161 & & 63 & \\
\hline
\end{tabular}

ote: NFP is not-for-profit; FP is for-profit; and GOV is government. 
Table 2: Production Function Parameter Estimates

\begin{tabular}{lcccccc}
\hline \hline & OLS & FE & DPD & ACF & OP & LP \\
Variable & $(1)$ & $(2)$ & $(3)$ & $(4)$ & $(5)$ & $(6)$ \\
\hline Labor, $l_{t}$ & $.790^{* *}$ & $.588^{* *}$ & $.781^{* *}$ & $.775^{* *}$ & $.901^{* *}$ & $.847^{* *}$ \\
& $(.028)$ & $(.070)$ & $(.046)$ & $(.028)$ & $(.019)$ & $(.024)$ \\
Capital, $k_{t}$ & $.096^{* *}$ & $.0862^{* *}$ & $.140^{* *}$ & $.182^{* *}$ & $.179^{* *}$ & $.125^{* *}$ \\
& $(.014)$ & $(.014)$ & $(.029)$ & $(.025)$ & $(.051)$ & $(.036)$ \\
IT Labor, $l_{t}^{c}$ & $.012^{* *}$ & $.011^{* *}$ & $.028^{* *}$ & $.009^{* *}$ & .004 & .003 \\
& $(.003)$ & $(.002)$ & $(.007)$ & $(.003)$ & $(.004)$ & $(.004)$ \\
IT Capital, $k_{t}^{c}$ & $.028^{* *}$ & $.026^{* *}$ & $.045^{* *}$ & $.033^{* *}$ & $.038^{* *}$ & $.033^{* *}$ \\
& $(.003)$ & $(.004)$ & $(.009)$ & $(.005)$ & $(.005)$ & $(.005)$ \\
$\rho$ & $.799^{* *}$ & $.555^{* *}$ & $.664^{* *}$ & - & - & - \\
& $(.028)$ & $(.034)$ & $(.046)$ & & & \\
\hline ComFac & .000 & .000 & .218 & - & - & - \\
\hline No of Obs. & 2,904 & 2,904 & 2,904 & 3,392 & 3,392 & 3,392 \\
No of Hosp. & 264 & 264 & 264 & 309 & 309 & 309 \\
\hline \hline
\end{tabular}

Note: FE is fixed-effects; DPD is dynamic panel data (Blundell/Bond); ACF is Ackerberg/Caves/Frazier; OP is Olley/Pakes and LP is Levinsohn/Petrin.

Standard errors are in parentheses.

$*: p<0.05, * *: p<0.01$ 
Table 3: DPD estimates by ownership type and tests of the presence of network effects

\begin{tabular}{lcccc}
\hline \hline Variable & FP & NFP & Government & $\begin{array}{c}\text { Network } \\
\text { effects } \\
\end{array}$ \\
& $(1)$ & $(2)$ & $(3)$ & $(4)$ \\
\hline Labor, $l_{t}$ & $.896^{* *}$ & $.597^{* *}$ & $.441^{* *}$ & $.830^{* *}$ \\
Capital, $k_{t}$ & $(.042)$ & $(.067)$ & $(.084)$ & $(.037)$ \\
& $.068^{* *}$ & $.081^{*}$ & $.099^{* *}$ & $.100^{* *}$ \\
IT Labor, $l_{t}^{c}$ & $(.025)$ & $(.037)$ & $(.036)$ & $(.021)$ \\
& $.026^{* *}$ & $.010^{*}$ & $.043^{* *}$ & $.026^{* *}$ \\
IT Capital, $k_{t}^{c}$ & $(.009)$ & $(.004)$ & $(.012)$ & $(.006)$ \\
& $.027^{* *}$ & $.035^{* *}$ & $.038^{* *}$ & $.041^{* *}$ \\
Neighbor's IT Labor, $l_{-i, t}^{c}$ & $(.009)$ & $(.008)$ & $(.009)$ & $(.008)$ \\
& - & - & - & -.002 \\
Neighbor's IT Capital, $k_{-i, t}^{c}$ & - & - & - & $-.011)$ \\
& & & & $(.001)$ \\
$\rho$ & $.641^{* *}$ & $.858^{* *}$ & $.882^{* *}$ & $.679^{* *}$ \\
& $(.046)$ & $(.038)$ & $(.026)$ & $(.043)$ \\
\hline ComFac & .149 & .010 & .000 & .334 \\
\hline No of Obs. & 697 & 1,616 & 591 & 2,556 \\
No of Hosp. & 63 & 147 & 54 & 232 \\
\hline
\end{tabular}

Note: NFP is not-for-profit and FP is for-profit. Standard errors are in parentheses. $*: p<0.05, * *: p<0.01$ 
Table 4: DPD estimates by bed size and time frame

\begin{tabular}{lcc|cc}
\hline \hline \multirow{2}{*}{ Variable } & $\leq \mathbf{1 7 3}$ beds & >173 beds & $\mathbf{1 9 9 7 - 2 0 0 1}$ & $\mathbf{2 0 0 2 - 2 0 0 7}$ \\
& $(1)$ & $(2)$ & $(3)$ & $(4)$ \\
\hline Labor, $l_{t}$ & $.718^{* *}$ & $.870^{* *}$ & $.441^{*}$ & $.783^{* *}$ \\
Capital, $k_{t}$ & $(.073)$ & $(.049)$ & $(.217)$ & $(.046)$ \\
& $.140^{* *}$ & $.084^{* *}$ & $.256^{* *}$ & $.142^{* *}$ \\
IT Labor, $l_{t}^{c}$ & $(.034)$ & $(.028)$ & $(.085)$ & $(.029)$ \\
& $.023^{* *}$ & $.013^{* *}$ & .005 & $.030^{* *}$ \\
IT Capital, $k_{t}^{c *}$ & $(.008)$ & $(.06)$ & $(.025)$ & $(.008)$ \\
& $.029^{* *}$ & $.034^{* *}$ & .047 & $.046^{* *}$ \\
$\rho$ & $(.009)$ & $(.011)$ & $(.044)$ & $(.009)$ \\
& $.773^{* *}$ & $.711^{* *}$ & $.824^{* *}$ & $.641^{* *}$ \\
\hline ComFac & $(.053)$ & $(.047)$ & $(.042)$ & $(.046)$ \\
\hline No of Obs. & .131 & .042 & .635 & .145 \\
No of Hosp. & 1,452 & 1,452 & 1,159 & 1,745 \\
\hline \hline
\end{tabular}

Note: Standard errors are in parentheses.

$*: p<0.05, * *: p<0.01$ 


\section{Appendix}

Table 5: ACF estimates by ownership type and tests of the presence of network effects

\begin{tabular}{lcccc}
\hline \hline Variable & FP & NFP & Government & $\begin{array}{c}\text { Network } \\
\text { effects } \\
\end{array}$ \\
& $(1)$ & $(2)$ & $(3)$ & $(4)$ \\
\hline Labor, $l_{t}$ & $0.809^{* *}$ & $0.780^{* *}$ & $0.610^{* *}$ & $0.796^{* *}$ \\
Capital, $k_{t}$ & $(0.051)$ & $(0.031)$ & $(0.081)$ & $(0.031)$ \\
& $0.139^{* *}$ & $0.185^{* *}$ & $0.201^{* *}$ & $0.172^{* *}$ \\
IT Labor, $l_{t}^{c}$ & $(0.033)$ & $(0.037)$ & $(0.042)$ & $(0.022)$ \\
& 0.007 & 0.006 & $0.025^{*}$ & 0.005 \\
IT Capital, $k_{t}^{c}$ & $(0.010)$ & $(0.003)$ & $(0.011)$ & $(0.003)$ \\
& $0.032^{*}$ & $0.038^{* *}$ & $0.034^{* *}$ & 0.036 \\
Neighbor's IT Labor, $l_{-i, t}^{c}$ & $(0.013)$ & $(0.005)$ & $(0.010)$ & $(0.006)$ \\
& & & & $-0.013^{* *}$ \\
Neighbor's IT Capital, $k_{-i, t}^{c}$ & & & & $(0.005)$ \\
& & & & -0.002 \\
No of Obs. & 856 & 1,859 & 677 & $(0.007)$ \\
No of Hosp. & 78 & 169 & 62 & 281 \\
\hline \hline
\end{tabular}

Note: NFP is not-for-profit and FP is for-profit. Standard errors are in parentheses.

$*: p<0.05, * *: p<0.01$

Table 6: ACF estimates by bed size and time frame

\begin{tabular}{lcc|cc}
\hline \hline Variable & $\leq \mathbf{1 7 3}$ beds & $\mathbf{1 7 3}$ beds & $\mathbf{1 9 9 7 - 2 0 0 1}$ & $\mathbf{2 0 0 2 - 2 0 0 7}$ \\
& $(1)$ & $(2)$ & $(3)$ & $(4)$ \\
\hline Labor, $l_{t}$ & $.768^{* *}$ & $.792^{* *}$ & $.717^{* *}$ & $.792^{* *}$ \\
Capital, $k_{t}$ & $(.054)$ & $(.030)$ & $(.073)$ & $(.048)$ \\
& $.172^{* *}$ & $.175^{* *}$ & $.244^{* *}$ & $.140^{* *}$ \\
IT Labor, $l_{t}^{c}$ & $(.022)$ & $(.029)$ & $(.039)$ & $(.037)$ \\
& $.011^{*}$ & $.010^{*}$ & -.0008 & $.012^{* *}$ \\
IT Capital, $k_{t}^{c}$ & $(.005)$ & $(.005)$ & $(.006)$ & $(.004)$ \\
& $.035^{* *}$ & $.025^{* *}$ & $.028^{* *}$ & $.036^{* *}$ \\
No of Obs. & $(.007)$ & $(.006)$ & $(.006)$ & $(.004)$ \\
No of Hosp. & 1,707 & 1,685 & 1,572 & 1,820 \\
\hline \hline
\end{tabular}

Note: Standard errors are in parentheses.

$*: p<0.05, * *: p<0.01$ 